OLIVEIRA, Eduardo Matos. Transformações no acesso à justiça: da expansão do judiciário às soluções alternativas de conflitos. Revista Eletrônica Direito e Política, Programa de Pós-Graduação Stricto Sensu em Ciência Jurídica da UNIVALI, Itajaí, v.13, n.1, 10 quadrimestre de 2018. Disponível em: www.univali.br/direitoepolitica - ISSN 1980-7791

\title{
TRANSFORMAÇÕES NO ACESSO À JUSTIÇA: DA EXPANSÃO DO JUDICIÁRIO ÀS SOLUÇÕES ALTERNATIVAS DE CONFLITOS
}

\author{
TRANSFORMATIONS IN THE ACESS TO JUSTICE: FROM THE EXPANSION OF \\ JUDICIAL POWER TO ALTERNATIVE DISPUTE RESOLUTION
}

\section{Eduardo Matos Oliveira ${ }^{1}$}

SÚMARIO: Introdução; 1 . A Construção do Judiciário no Ocidente: Os Estudos Judiciais na Ciência Política; 2. O Acesso à Justiça: Teoria e Debates; 3. Mudanças Recentes na Política de Acesso à Justiça no Brasil; Considerações Finais; Referência das fontes citadas.

\section{RESUMO}

Embora tradicionalmente a questão do acesso à justiça tenha sido abordada em debates jurídicos, em especial no campo processual, a Ciência Política vem gradualmente oferecendo contribuições importantes para engendrar um diálogo interdisciplinar. O objetivo deste artigo é incorporar contribuições da Ciência Política ao debate do acesso à justiça no Brasil, em especial, no que se refere à questão da a obrigatoriedade da conciliação e mediação no novo Código de Processo Civil. Debates importantes do acesso à justiça serão retomados a fim de introduzir as discussões atuais. As conclusões indicam a necessidade de maior integração entre as pesquisas empíricas realizadas no âmbito da Ciência Política e os estudos jurídicos, a fim de que os resultados das reformas processuais sejam testados e as modificações na política sejam realizadas de forma mais precisa.

Palavras-chave: Acesso à Justiça; Judiciário; Soluções Alternativas de Conflitos

\begin{abstract}
Although the issue of access to justice has been traditionally addressed in legal debates, especially in procedural law, Political Science has gradually been making important contributions to engender an interdisciplinary dialogue. The objective is to incorporate contributions of Political Science to the debate on access to justice in Brazil, especially with regard to the issue of mandatory conciliation and mediation in the new legislation. Important debates for the literature on access to justice are going to be analyzed in order to introduce the current discussions. Conclusions indicate the necessity of greater integration between empirical research that is done in Political Science and legal studies, so that the results of reforms could be tested and modifications would be done more precisely.
\end{abstract}

Keywords: Access to Justice; Judiciary; Alternative Dispute Resolution.

\footnotetext{
${ }^{1}$ Doutorando e mestre em Ciência Política na Universidade Federal de Pernambuco. Bacharel em Direito na Faculdade de Direito do Recife/UFPE. Advogado. Membro do Núcleo de Pesquisas Regionais e do Desenvolvimento (UFPE). E-mail: eduardo.matos.oliveira@gmail.com.
} 
OLIVEIRA, Eduardo Matos. Transformações no acesso à justiça: da expansão do judiciário às soluções alternativas de conflitos. Revista Eletrônica Direito e Política, Programa de Pós-Graduação Stricto Sensu em Ciência Jurídica da UNIVALI, Itajaí, v.13, n.1, $1^{\circ}$ quadrimestre de 2018. Disponível em: www.univali.br/direitoepolitica - ISSN 1980-7791

\section{INTRODUÇÃO}

Os debates a respeito do acesso à justiça no direito e na teoria política avançaram sensivelmente nas últimas décadas. Apesar de ainda existir entraves, a assistência judiciária para as populações menos favorecidas se desenvolveu, o arcabouço normativo para proteção dos direitos coletivos e difusos se tornou realidade e, atualmente, as soluções alternativas de conflitos estão no centro das discussões em virtude da Lei de Mediação (13.140/2015) e das mudanças no Novo Código de Processo Civil.

Embora tradicionalmente a questão do acesso à justiça tenha sido abordada em debates jurídicos, em especial no campo processual, a Ciência Política vem gradualmente oferecendo contribuições importantes para engendrar um diálogo interdisciplinar. Neste artigo, o problema da pesquisa se desenvolve a partir de como a teoria política e o direito enxergam o papel do judiciário em termos do acesso à justiça. O objetivo do artigo é incorporar contribuições da Ciência Política ao debate do acesso à justiça no Brasil, em especial, no que se refere à questão da a obrigatoriedade da conciliação e mediação no novo Código de Processo Civil

Conforme será detalhado no primeiro tópico, os estudos judiciais na teoria política e no direito ganharam muito destaque, especialmente, após o fenômeno da judicialização da política, ou seja, a intervenção do judiciário nas ações do executivo ou na dinâmica do legislativo. Portanto, percebe-se a necessidade de retomar os debates a respeito não só do Judiciário enquanto Poder Político do Estado, mas também na sua função essencial de resolução dos conflitos na sociedade.

No segundo tópico, serão trazidas as principais teorias que tentam explicar as mudanças estruturais na prestação do serviço judicial, em especial, a abordagem institucional das ondas de acesso à justiça em contraposição à explicação econômica ligada ao surgimento e queda do Estado de Bem-Estar Social.

Em seguida, serão discutidas as mudanças ocorridas com a reforma do Judiciário e, posteriormente, a inserção dos meios alternativos de resolução de conflitos. É 
OLIVEIRA, Eduardo Matos. Transformações no acesso à justiça: da expansão do judiciário às soluções alternativas de conflitos. Revista Eletrônica Direito e Política, Programa de Pós-Graduação Stricto Sensu em Ciência Jurídica da UNIVALI, Itajaí, v.13, n.1, 10 quadrimestre de 2018. Disponível em: www.univali.br/direitoepolitica - ISSN 1980-7791

feita uma ressalva, a partir de uma literatura preocupada com questões empíricas, ao uso indiscriminado da conciliação, mediação e arbitragem como uma panaceia que possa resolver todos os males do acesso à justiça.

Conclui-se com a necessidade de maior integração entre os estudos empíricos realizados no âmbito da Ciência Política e o Direito, a fim de testar os efeitos práticos das reformas processuais adotadas e pensar uma política nacional de acesso à justiça mais adequada às diversas realidades encontradas no Judiciário.

\section{A CONSTRUÇÃO DO JUDICIÁRIO NO OCIDENTE: OS ESTUDOS JUDICIAIS NA CIÊNCIA POLÍTICA}

Segundo Rogério Arantes ${ }^{2}$, após as revoluções liberais do século XVIII e XIX houve uma profunda reestruturação no processo de promoção da Justiça e resolução dos conflitos na sociedade. Durante os regimes absolutistas, a magistratura era exercida pelos membros da nobreza sem que houvesse uma profissionalização ou reconhecimento destas funções como parte autônoma do poder estatal. Após a queda do antigo regime, surge a ideia de um Judiciário como parte integrante do Estado e até como poder político.

Dois modelos bastante distintos de Judiciário surgiram neste período ${ }^{3}$. O primeiro foi da revolução francesa, que entendia a instituição apenas como prestadora de um serviço público e mediação dos litígios. Inclusive, Montesquieu ${ }^{4}$ não atribuiu ao Judiciário a mesma condição política do Executivo e Legislativo, já que o filósofo pensou em freios e contrapesos apenas para estes dois últimos, que seriam os poderes ativos. Em resumo, conforme coloca Arantes 5 "a interpretação

\footnotetext{
2 ARANTES, Rogério B. "Judiciário: entre a Justiça e a Política" In: Lúcia Avelar; Antônio Octávio Cintra. (Org.). Sistema Político Brasileiro: uma introdução. São Paulo: Editora UNESP, 2014 , p. 30.
}

3 ARANTES, Rogério B. "Judiciário: entre a Justiça e a Política" In: Lúcia Avelar; Antônio Octávio Cintra. (Org.). Sistema Político Brasileiro: uma introdução, p. 30.

4 MONTESQUiEU. O Espírito das Leis. São Paulo: Martins Fontes, 1996, p. 167-178 apud ARANTES, Rogério B. "Judiciário: entre a Justiça e a Política" In: Lúcia Avelar; Antônio Octávio Cintra. (Org.). Sistema Político Brasileiro: uma introdução, p. 31.

5 ARANTES, Rogério B. "Judiciário: entre a Justiça e a Política" In: Lúcia Avelar; Antônio Octávio Cintra. (Org.). Sistema Político Brasileiro: uma introdução, p. 31. 
OLIVEIRA, Eduardo Matos. Transformações no acesso à justiça: da expansão do judiciário às soluções alternativas de conflitos. Revista Eletrônica Direito e Política, Programa de Pós-Graduação Stricto Sensu em Ciência Jurídica da UNIVALI, Itajaí, v.13, n.1, $1^{\circ}$ quadrimestre de 2018. Disponível em: www.univali.br/direitoepolitica - ISSN 1980-7791

da obra de Montesquieu que habita o senso comum e pela qual o Judiciário seria um terceiro poder de Estado deve ser bastante relativizada".

A tradição francesa está associada à escola da exegese do positivismo jurídico 6 que enxergava o julgador apenas como "boca da lei", ou seja, caberia ao juiz apenas identificar a "vontade do legislador". Ou seja, fazer a subsunção, que seria identificar legislação específica aplicável ao caso concreto, por conseguinte o magistrado, em nenhuma hipótese, poderia inovar através da interpretação da lei. Por isso, a função judicial era vista como algo menor em relação às demais funções do Estado.

O segundo modelo surgido nas revoluções liberais é o norte-americano, que enxerga o Judiciário não apenas como órgão de promoção da justiça e pacificação de conflitos, mas também como poder político do Estado. O contexto político e social no período pós-revolucionário desempenhou uma influência sobre a doutrina pregada pelos responsáveis por desenhar o novo sistema institucional. Os líderes da revolução norte-americana temiam que a supremacia do parlamento pudesse ocasionar a união de grupos populares contra a nova ordem instituída. A citação abaixo, retirada dos artigos federalistas, desenvolve o argumento:

É de grande importância numa república não apenas proteger a sociedade contra a opressão de seus governantes, mas proteger uma parte da sociedade contra a injustiça da outra. Existem necessariamente diferentes interesses em diferentes classes de cidadãos. Se uma maioria estiver unida por um interesse comum, os direitos da minoria ficarão ameaçados ${ }^{7}$.

Para resolver o problema da opressão da maioria sobre a minoria, Madison, Hamilton e Jay propuseram transformar o Judiciário em poder político. Segundo os autores, esta solução visa proteger a Constituição de mudanças arbitrárias que pudessem ser propostas pela eventual maioria do parlamento. Portanto,

${ }^{6}$ BITTAR, Eduardo; ALMEIDA, Guilherme Assis de. Curso de Filosofia do Direito. São Paulo: Editora Atlas, 2009, p. 366.

7 MADISON, James; HAMILTON, Alexander; JAY, John. Os Artigos Federalistas, 1787-1788. Rio de Janeiro: Editora Nova Fronteira, 1993, p. 351. 
OLIVEIRA, Eduardo Matos. Transformações no acesso à justiça: da expansão do judiciário às soluções alternativas de conflitos. Revista Eletrônica Direito e Política, Programa de Pós-Graduação Stricto Sensu em Ciência Jurídica da UNIVALI, Itajaí, v.13, n.1, 10 quadrimestre de 2018. Disponível em: www.univali.br/direitoepolitica - ISSN 1980-7791

nesse momento surge doutrinariamente a proposta de dotar os tribunais com o poder de declarar a nulidade de atos legislativos, por serem contrários a Constituição.

Madison et. al $^{8}$ colocam que deveria haver limitações ao Poder Legislativo como por exemplo "a de que ele não aprovará decretos de perda de direitos civis, leis ex post facto, ou coisas semelhantes." E que "Na prática, limitações desse tipo não podem ser preservadas senão por meio dos tribunais de justiça". Os autores certamente colocam o Judiciário em outro patamar ao afirmar que ele deveria ser o intermediário entre o povo e o Legislativo, a fim de impedir que os representantes do povo substituam a vontade de seus eleitores pela sua própria 9 .

É necessário frisar que o Judiciário é alçado a condição de poder político do Estado por meio da sua capacidade de controlar os atos normativos dos demais poderes, especialmente as leis produzidas pelo parlamento ${ }^{10}$. Portanto, a partir do momento em que o controle de constitucionalidade se torna uma realidade, o Judiciário passa a participar da dimensão mais importante do Estado, que é o processo de elaboração das normas jurídicas.

Entretanto, o sistema madisoniano é alvo de críticas em função do seu caráter contra majoritário, conforme destaca Robert Dahl:

A ideologia madisoniana serviu como racionalização conveniente a todas as minorias que, temendo possíveis privações por iniciativa de alguma maioria, exigem um sistema político que lhes dê oportunidade de vetar tais políticas. (...) uma ideologia satisfatória, convincente e protetora às minorias de riqueza, status e poder, que sentiam

\footnotetext{
8 MADISON, James; HAMILTON, Alexander; JAY, John. Os Artigos Federalistas, 1787-1788, p. 480.

9 MADISON, James; HAMILTON, Alexander; JAY, John. Os Artigos Federalistas, 1787-1788, p. 481 .

10 ARANTES, Rogério B. "Judiciário: entre a Justiça e a Política" In: Lúcia Avelar; Antônio Octávio Cintra. (Org.). Sistema Político Brasileiro: uma introdução, p. 30.
} 
OLIVEIRA, Eduardo Matos. Transformações no acesso à justiça: da expansão do judiciário às soluções alternativas de conflitos. Revista Eletrônica Direito e Política, Programa de Pós-Graduação Stricto Sensu em Ciência Jurídica da UNIVALI, Itajaí, v.13, n.1, $1^{\circ}$ quadrimestre de 2018. Disponível em: www.univali.br/direitoepolitica - ISSN 1980-7791

profunda desconfiança e temor de seus acerbos inimigos - os artesãos e agricultores, de riqueza, status e poder inferiores, que elas julgavam constituir a "maioria popular"11.

O autor continua argumentando que a democracia idealizada por Madison se mostrou claramente inadequada, visto que não conseguiu conciliar dois objetivos conflitantes. O primeiro seria a garantia que todos deveriam ter direitos iguais garantidos, inclusive a possibilidade de influir na política pública. Neste sentido, haveria o governo da maioria. Porém, o segundo objetivo seria garantir as liberdades de minorias que possuíam maior status e riqueza, impedindo que a maioria restringisse os direitos destes grupos. A tentativa de acomodar estas duas metas conflitas determinou o fracasso da democracia madisoniana ${ }^{12}$.

Apesar da ideia da revisão judicial dos atos legislativos ter surgido nos artigos federalistas, a Constituição norte-americana, elaborada em 1787, não aderiu ao instituto. Foi apenas em 1803, através de uma decisão da própria suprema corte que o controle de constitucionalidade foi instituído no sistema político dos Estados Unidos. Conforme destaca Ernani Carvalho ${ }^{13}$ "os pilares que ergueram a possibilidade de o Judiciário intervir no processo decisório dos países ocidentais foram estabelecidos no caso Marbury versus Madison pelo Chief Justice John Marshall". É curioso que a medida tenha sido adotada por meio do próprio Poder Judiciário.

O modelo de controle de constitucionalidade criado nos Estados Unidos ficou conhecido como "modelo difuso", visto que pode ser realizado em qualquer grau de jurisdição. A compatibilidade da lei em relação à Constituição é feita no caso concreto, não sendo avaliada em abstrato. Naturalmente, a última palavra a respeito da interpretação cabe à suprema corte, que orienta os tribunais

${ }^{11}$ DAHL, Robert. Um Prefácio à Teoria Democrática. Rio de Janeiro: Jorge Zahar Editor, 1989, p. 35.

12 DAHL, Robert. Um Prefácio à Teoria Democrática, p. 35.

13 CARVALHO, Ernani. Revisão Judicial e Judicialização da Política no Direito Ocidental: Aspectos relevantes de sua gênese e desenvolvimento. Revista de Sociologia e Política, n. 28, p. 161179, 2007, p. 165. 
OLIVEIRA, Eduardo Matos. Transformações no acesso à justiça: da expansão do judiciário às soluções alternativas de conflitos. Revista Eletrônica Direito e Política, Programa de Pós-Graduação Stricto Sensu em Ciência Jurídica da UNIVALI, Itajaí, v.13, n.1, 10 quadrimestre de 2018. Disponível em: www.univali.br/direitoepolitica - ISSN 1980-7791

inferiores a decidirem de acordo com a nova orientação a respeito daquele caso $^{14}$.

Na Europa, a influência da tradição francesa do Judiciário sem poder político foi dominante durante o século XIX e o início do século XX. Embora os tribunais constitucionais já existissem anteriormente, foi somente ao final da segunda guerra mundial que eles foram amplamente adotados no continente. Com os horrores das guerras e o surgimento dos fascismos, as elites políticas da Europa se convenceram que seria necessário estabelecer algum limite para a vontade da maioria e a supremacia do parlamento, a fim de evitar a supressão de direitos civis e políticos em larga escala novamente.

O filósofo responsável por desenhar o modelo que seria implantado no continente foi Hans Kelsen. Ao contrário da ideia norte-americana de um controle difuso, Kelsen concebeu um sistema completamente diferente. Para ele, as cortes constitucionais deveriam ser um órgão separado do Judiciário e apenas julgar a constitucionalidade das leis em abstrato ${ }^{15}$. A primeira corte constitucional criada a partir do modelo de Kelsen foi a austríaca, prevista na Constituição de 1920. A Itália em 1948 e a Alemanha em 1949 adotaram o modelo de Kelsen, outros países preferiram um modelo híbrido, uma mistura do controle concentrado com o difuso.

Mesmo nos dias atuais após a consolidação do Judiciário enquanto poder político através do controle de constitucionalidade, o debate ainda está vivo e muitas contestações à revisão judicial dos atos normativos são pertinentes. Por exemplo, Jeremy Waldron, em 2006, publicou um artigo chamado "The Core of the Case Against Judicial Review" em que apresenta argumentos normativos contra a utilização da revisão judicial. Para o autor, é necessário analisar a questão despindo-se de questões históricas, visto que frequentemente os

\footnotetext{
14 CARVALHO, Ernani. Revisão Judicial e Judicialização da Política no Direito Ocidental: Aspectos relevantes de sua gênese e desenvolvimento, p. 166.

15 KELSEN, Hans. Quem deve ser o Guardião da Constituição? In: KELSEN, Hans. Jurisdição Constitucional. São Paulo: Editora Martins Fontes, 2003, p. 248.
} 
OLIVEIRA, Eduardo Matos. Transformações no acesso à justiça: da expansão do judiciário às soluções alternativas de conflitos. Revista Eletrônica Direito e Política, Programa de Pós-Graduação Stricto Sensu em Ciência Jurídica da UNIVALI, Itajaí, v.13, n.1, $1^{\circ}$ quadrimestre de 2018. Disponível em: www.univali.br/direitoepolitica - ISSN 1980-7791

opositores do controle de constitucionalidade variam de acordo com os resultados dos julgamentos das cortes constitucionais ${ }^{16}$.

Portanto, ele apresenta duas posições; primeiramente o fato de que a revisão judicial não garante um debate amplo e irrestrito na sociedade a respeito do tema que está em jogo, já que há distrações a respeito de precedentes, textos legais e interpretações. Em segundo lugar, o processo é ilegítimo democraticamente, uma vez que a vontade da maioria está sendo substituída pela decisão de um pequeno corpo de juízes, que não se submetem ao voto popular, nem possuem nenhuma forma de serem responsabilizados pelos seus atos. Consequentemente, essa ilegitimidade faz com que os princípios da representatividade e igualdade política sejam deixados de lado, inclusive quando há uma decisão final da corte sobre esses direitos ${ }^{17}$.

Além do mais, Robert Dahl18 coloca que "quando o processo democrático não pode mais ser sustentado em face de uma cultura política fraca ou hostil, é difícil crer que os direitos políticos primários serão preservados por muito mais tempo pelos tribunais". Ou seja, para o autor, a única forma de preservar verdadeiramente os direitos básicos dos diferentes grupos sociais é o amadurecimento da cultura democrática, e não confiar essa responsabilidade para um pequeno grupo de "notáveis".

Por outro lado, Ronald Dworkin ${ }^{19}$ argumenta em defesa da revisão judicial afirmando que o debate acima está desfocado, uma vez que assume a decisão pela maioria como o melhor processo decisório em termos normativos. Para ele, a verdadeira discussão é a respeito de qual o valor ou objetivo fundamental da democracia. A premissa majoritária é "uma tese a respeito dos resultados justos

\footnotetext{
${ }^{16}$ WALDRON, Jeremy. The Core of the Case Against Judicial Review. The Yale Law Journal, $\mathrm{n}$. 115,2006, p. 1351.

17 WALDRON, Jeremy. The Core of the Case Against Judicial Review, p. 1353.

${ }^{18}$ DAHL, Robert. A Democracia e seus Críticos. São Paulo: Editora WMF Martins Fontes, 2012, p. 273.
}

19 DWORKIN, Ronald. O Direito da Liberdade - A Leitura Moral da Constituição NorteAmericana. São Paulo: Editora Martins Fontes, 2006. 
OLIVEIRA, Eduardo Matos. Transformações no acesso à justiça: da expansão do judiciário às soluções alternativas de conflitos. Revista Eletrônica Direito e Política, Programa de Pós-Graduação Stricto Sensu em Ciência Jurídica da UNIVALI, Itajaí, v.13, n.1, $1^{\circ}$ quadrimestre de 2018. Disponível em: www.univali.br/direitoepolitica - ISSN 1980-7791

de um processo político"20, o que é bastante razoável, porém este não é o fundamento basilar da democracia, já que esta premissa pressupõe ser injusto sempre que a maioria política não pode fazer o que quiser.

Ronald Dworkin, então, propõe uma concepção constitucional de democracia em que o objetivo da democracia é que "as decisões coletivas sejam tomadas por instituições políticas cuja estrutura, composição e modo de operação dediquem a todos os membros da comunidade, enquanto indivíduos, a mesma consideração e o mesmo respeito"21. Portanto, esta concepção pode adotar a premissa majoritária, porém não em virtude de um compromisso com a soberania absoluta da maioria, mas sim uma preocupação com a igualdade política dos cidadãos. E também não se opõe ao emprego de soluções contra majoritárias em ocasiões especiais.

Além da mudança de referencial, Dworkin ainda argumenta a respeito da necessidade de fundamentação das decisões judiciais e de sua integração com a Constituição, o que ele considera uma limitação ao poder dos juízes. Por fim, em outro texto Dworkin ${ }^{22}$ faz a distinção entre "questões insensíveis à escolha" e "questões sensíveis à escolha". As primeiras são tópicos que independem da vontade da maioria, como por exemplo os direitos políticos da população negra, mesmo que a maioria absoluta desejasse suprimi-los, esta não deveria ser uma escolha possível. Por isso, estas questões devem ser fruto de revisão constitucional para defender as garantias básicas. Entretanto, as questões sensíveis à escolha (da maioria) são relacionadas à política pública em geral e não devem sofrer interferência do Judiciário.

Independentemente da posição adotada no debate acima, o fato é que houve uma grande expansão do Poder Judiciário no século XX. O livro organizado por

20 DWORKIN, Ronald. O Direito da Liberdade - A Leitura Moral da Constituição NorteAmericana, p. 24.

21 DWORKIN, Ronald. O Direito da Liberdade - A Leitura Moral da Constituição NorteAmericana, p. 26.

22 DWORKIN, Ronald. A Virtude Soberana - A Teoria e a Prática da Igualdade. São Paulo, Editora Martins Fontes, 2011, p. 289. 
OLIVEIRA, Eduardo Matos. Transformações no acesso à justiça: da expansão do judiciário às soluções alternativas de conflitos. Revista Eletrônica Direito e Política, Programa de Pós-Graduação Stricto Sensu em Ciência Jurídica da UNIVALI, Itajaí, v.13, n.1, $1^{\circ}$ quadrimestre de 2018. Disponível em: www.univali.br/direitoepolitica - ISSN 1980-7791

Neil Tate e Torbjorn Vallinder ${ }^{23}$ traz uma série de estudos sobre o tema. A análise dos casos leva a conclusão que mesmo em países com a tradição do civil law, onde os juízes teoricamente somente aplicam os códigos e as leis, há uma intensa judicialização da política ${ }^{24}$. O processo na Alemanha e Itália, por exemplo, pode ser explicado pelas guerras e fascismos, e a posterior criação do tribunal constitucional, conforme discutimos acima. Porém, países como a Holanda, Suécia, Malta e Israel também apresentam uma grande expansão do papel judicial, mesmo que sem uma causa evidente catalisando o fenômeno ${ }^{25}$.

Em termos teóricos, os autores associam diretamente a expansão do Judiciário no século XX ao fenômeno da judicialização da política ${ }^{26}$. Ou seja, ao discutir a expansão do Judiciário, os autores não consideram sua dimensão de prestação de um serviço público ao cidadão comum, mas sim sua função enquanto poder do Estado.

Apesar do grande protagonista da judicialização da política ser o controle de constitucionalidade, que foi a inovação responsável por alçar o Judiciário à função de poder político, também há outras formas de judicialização. Por exemplo, observa-se atualmente a expansão dos setores jurídicos e métodos judiciais de decisão dentro dos órgãos administrativos do Poder Executivo27. Outro fenômeno que chama atenção é a intervenção de juízes, inclusive de primeira instância, nas políticas públicas que antes eram responsabilidade exclusiva do Legislativo e Executivo.

\footnotetext{
23 TATE, Neal; VALLINDER, Torbjörn. The Global Expansion of Judicial Power. New York: New York University Press, 1995.

24 TATE, Neal; VALLINDER, Torbjörn. The Global Expansion of Judicial Power, p. 518.

25 TATE, Neal; VALLINDER, Torbjörn. The Global Expansion of Judicial Power, p. 522.

26 TATE, Neal; VALLINDER, Torbjörn. The Global Expansion of Judicial Power, p. 13.

27 TATE, Neal; VALLINDER, Torbjörn. The Global Expansion of Judicial Power, p. 16.
} 
OLIVEIRA, Eduardo Matos. Transformações no acesso à justiça: da expansão do judiciário às soluções alternativas de conflitos. Revista Eletrônica Direito e Política, Programa de Pós-Graduação Stricto Sensu em Ciência Jurídica da UNIVALI, Itajaí, v.13, n.1, $1^{\circ}$ quadrimestre de 2018. Disponível em: www.univali.br/direitoepolitica - ISSN 1980-7791

John Farejohn ${ }^{28}$ acrescenta ainda que o processo de judicialização mudou profundamente a relação entre os poderes do Estado, já que os grupos políticos no parlamento ao negociar suas ações precisam levar em consideração a possibilidade de reação judicial àquele ato. Ou seja, a legislação precisa ser elaborada de forma que não seja interpretada de modo diferente do planejado. Além disso, há também a judicialização dos próprios procedimentos parlamentares, que no Brasil se tornaram tão recorrentes por meio do instituto do mandado de segurança por parte dos deputados e senadores.

Para o autor, a consequência direta da judicialização da política é a politização do Judiciário. À medida que os tribunais tomam decisões com efeitos políticos relevantes, naturalmente, aqueles que tem interesse nos resultados dos julgamentos terão motivos para tentar influenciar ou controlar as indicações dos magistrados para as cortes superiores ${ }^{29}$. Apesar das indicações inevitavelmente serem políticas, o que é legítimo, elas não precisam ser partidárias, visto que as coalizões vencedoras irão mudar e se as interpretações constitucionais sempre flutuarem dessa forma haverá uma grande instabilidade jurídica.

A judicialização da política, a politização do Judiciário e todos os debates mostrados acima foram trazidos a fim de evidenciar o fato de que a teoria política contemporânea ligada ao direito foca sobremaneira no estudo do Judiciário como poder político, enquanto que a função judicial de resolver conflitos na sociedade é pouco explorada no campo. A partir dos dois modelos de Judiciário surgidos na revolução norte-americana e na francesa, o modelo americano predominou não só na expansão global do Judiciário, mas também nos estudos presentes no ambiente acadêmico.

Quando se discute o tema do "Judiciário e as Políticas Públicas", como por exemplo no artigo publicado por Matthew Taylor $^{30}$ com esse título, trata-se de

${ }^{28}$ FAREJOHN, John. Judicializing Politics, Politicizing Law. Law and Contemporary Problems, vol. 65, n. 3, 2002, p. 42.

${ }^{29}$ FAREJOHN, John. Judicializing Politics, Politicizing Law, p. 63.

30 TAYLOR, Matthew. O Judiciário e as Políticas Públicas no Brasil. DADOS - Revista de Ciências Sociais, vol. 50, n. 2, p. 229-257, 2007. 
OLIVEIRA, Eduardo Matos. Transformações no acesso à justiça: da expansão do judiciário às soluções alternativas de conflitos. Revista Eletrônica Direito e Política, Programa de Pós-Graduação Stricto Sensu em Ciência Jurídica da UNIVALI, Itajaí, v.13, n.1, 10 quadrimestre de 2018. Disponível em: www.univali.br/direitoepolitica - ISSN 1980-7791

um debate sobre a interferência dos juízes nas funções do Poder Executivo e Legislativo, e não um debate a respeito de uma política pública de acesso à justiça. Conforme o autor esclarece na introdução do trabalho, o foco é a análise do sistema político:

O Poder Judiciário possui um impacto significativo na elaboração das políticas públicas: (...) Cada vez mais, a visão clássica dos tribunais como instâncias estritamente legais tem sido contestada pelas crescentes evidências de seu papel político e de seu impacto diário nas políticas públicas. (...) O proposito deste artigo é pensar sistematicamente o papel do judiciário no sistema político brasileiro e, em particular, na formação de políticas públicas ${ }^{31}$.

Apesar da importância incontestável da função política do Poder Judiciário para os debates acadêmicos, não se pode desprezar sua outra face, que é a prestação de um serviço público fundamental para a sociedade.

\section{O ACESSO À JUSTIÇA: TEORIA E DEBATES}

No Estado Democrático de Direito, o acesso à justiça constitui um pilar fundamental, uma vez que sem essa garantia nenhum outro direito pode ser assegurado. Conforme destaca Maria Tereza Sadek ${ }^{32}$ "Os direitos são letra morta na ausência de instâncias que garantam seu cumprimento". Portanto, além do estudo do Judiciário enquanto poder político constitucional, é necessário aprofundar questões referentes à utilização do aparato judicial pelo cidadão comum. O trecho abaixo esclarece melhor este processo:

(...) fato é que o judiciário conheceu forte expansão na segunda metade do século $X X$, transformando-se em instância de solução de conflitos coletivos e sociais e de implementação de direitos orientados pelo valor da igualdade e não só pelo valor da liberdade. Isso obrigou os judiciários de diversas democracias a reverem suas finalidades institucionais, pautadas no paradigma liberal, e a se reencontrarem com a

\footnotetext{
31 TAYLOR, Matthew. O Judiciário e as Políticas Públicas no Brasil, p. 229.

32 SADEK, Maria Tereza (org.). Acesso à Justiça. São Paulo: Fundação Konrad Adenauer, 2001, p. 7.
} 
OLIVEIRA, Eduardo Matos. Transformações no acesso à justiça: da expansão do judiciário às soluções alternativas de conflitos. Revista Eletrônica Direito e Política, Programa de Pós-Graduação Stricto Sensu em Ciência Jurídica da UNIVALI, Itajaí, v.13, n.1, $1^{\circ}$ quadrimestre de 2018. Disponível em: www.univali.br/direitoepolitica - ISSN 1980-7791

dimensão política não pela via da justiça constitucional, mas pela porta da justiça comum ${ }^{33}$.

A grande importância do Judiciário como principal instância de resolução dos conflitos na sociedade consiste na tentativa de evitar que os indivíduos pratiquem a "justiça com as próprias mãos", ou seja, que as soluções privadas sejam predominantes. Em larga escala, se o Estado não consegue ser o árbitro maior dos litígios e todos aplicarem a solução que acharem conveniente para seus problemas, estaremos perto do Estado de Natureza descrito por Thomas Hobbes no Leviatã.

No Brasil, segundo dados do IPEA de 2010 apresentados por Sadek ${ }^{34}$, 63\% dos indivíduos que declararam ter vivenciado um problema sério não buscaram o Judiciário para resolver a questão. Por conseguinte, torna-se evidente que a via judicial não é o principal meio de solucionar os litígios na sociedade brasileira. Porém, isto não significa que todos os casos sejam resolvidos através da "lei do mais forte".

Normalmente, duas formas diferentes podem substituir a ação do Estado, a primeira é o apelo à violência e a segunda é a utilização de organizações não estatais que resolvem os problemas através de meios informais. Associações de moradores do bairro, clubes ou igrejas podem exercer este papel ${ }^{35}$. Esta segunda forma pode ser benéfica para a coletividade, visto que a sociedade civil se organiza para resolver seus conflitos sem necessariamente precisar de uma terceira parte para impor a decisão.

Há ainda uma terceira possibilidade no Brasil, que é a execução de práticas tipicamente judiciais realizadas pela polícia na resolução de casos considerados

\footnotetext{
33 ARANTES, Rogério B. "Judiciário: entre a Justiça e a Política" In: Lúcia Avelar; Antônio Octávio Cintra. (Org.). Sistema Político Brasileiro: uma introdução, p. 51.

34 SADEK, Maria Tereza. Acesso à Justiça: Um direito e seus Obstáculos. Revista USP, n. 101, p. 55-66, 2014, p. 60.

35 SADEK, Maria Tereza. O Sistema de Justiça. Rio de Janeiro: Centro Edelstein de Pesquisas Sociais, 2010, p. 5.
} 
OLIVEIRA, Eduardo Matos. Transformações no acesso à justiça: da expansão do judiciário às soluções alternativas de conflitos. Revista Eletrônica Direito e Política, Programa de Pós-Graduação Stricto Sensu em Ciência Jurídica da UNIVALI, Itajaí, v.13, n.1, 10 quadrimestre de 2018. Disponível em: www.univali.br/direitoepolitica - ISSN 1980-7791

menores. O fenômeno foi observado por Luciano Oliveira ${ }^{36} \mathrm{em}$ estudo publicado originalmente nos anos 1980 com o título "Sua Excelência o Comissário", em que o autor fez um levantamento nas periferias de Recife. A pesquisa destaca o fato de que a autoridade policial resolve os conflitos dos indivíduos de baixa renda sem encaminhar o processo para o juiz e o Ministério Público, especialmente questões relacionadas a ofensas morais, agressões e desordem.

Interessante acrescentar que segundo o autor, as pessoas não procuram as soluções alternativas para resolução de conflitos após se depararem com as inacessibilidades do Judiciário. Pelo contrário, historicamente, os delitos de natureza pessoal no Brasil, referentes às classes mais pobres, sempre esteve em outras mãos que não o Judiciário. Inclusive, o código criminal do império de 1830 estabelecia competência judicial para a polícia em relação aos delitos citados acima ${ }^{37}$.

Considerando que o acesso da população mais pobre ao Judiciário é escasso, cabe o questionamento de quem utiliza os serviços judiciais com maior frequência. Em levantamento feito pelo Conselho Nacional de Justiça em 2011 foi compilada a lista com os "Cem Maiores Litigantes". Abaixo segue a lista com os 10 primeiros lugares:

36 OLIVEIRA, Luciano. Sua Excelência o Comissário e outros ensaios de Sociologia Jurídica. Rio de Janeiro: Editora Letra Legal, 2004.

37 OLIVEIRA, Luciano. Sua Excelência o Comissário e outros ensaios de Sociologia Jurídica, p. 47. 
OLIVEIRA, Eduardo Matos. Transformações no acesso à justiça: da expansão do judiciário às soluções alternativas de conflitos. Revista Eletrônica Direito e Política, Programa de Pós-Graduação Stricto Sensu em Ciência Jurídica da UNIVALI, Itajaí, v.13, n.1, $1^{\circ}$ quadrimestre de 2018. Disponível em: www.univali.br/direitoepolitica - ISSN 1980-7791

Quadro 1: Os 10 maiores litigantes do Judiciário no Brasil

\begin{tabular}{|c|c|}
\hline RANK & LITIGANTES \\
\hline $\mathbf{1 0}^{\mathbf{0}}$ & INSS - Instituto Nacional do Seguro Social \\
\hline $\mathbf{2 0}^{\mathbf{0}}$ & Caixa Econômica Federal \\
\hline $\mathbf{3 0}^{\mathbf{0}}$ & Fazenda Nacional \\
\hline $\mathbf{4 0}^{\mathbf{0}}$ & União \\
\hline $\mathbf{5 0}^{\mathbf{0}}$ & Banco do Brasil S/A \\
\hline $\mathbf{6 0}^{\mathbf{0}}$ & Estado do Rio Grande do Sul \\
\hline $\mathbf{7 0}^{\mathbf{0}}$ & Banco Bradesco S/A \\
\hline $\mathbf{8 0}^{\circ}$ & Banco Itaú S/A \\
\hline $\mathbf{9 0}^{\mathbf{0}}$ & Brasil Telecom S/A \\
\hline $\mathbf{1 0}^{\circ}$ & Banco Finasa S/A \\
\hline
\end{tabular}

Fonte: CNJ. Cem Maiores Litigantes.

Ao analisar a tabela, percebe-se o predomínio da presença de órgãos, entes e empresas estatais em conjunto com bancos privados. Após o decimo lugar, o mesmo padrão continua se repetindo com o acréscimo de municípios, seguradoras e empresas de telefonia. Mais importante que a posição no rank de maiores litigantes é o fato de que o setor público no Brasil é responsável por $51 \%$ dos processos em tramitação no Judiciário. Além disso, a maior parte das ações contra a União em busca de medicamentos e internações são propostas por pessoas com plano de saúde particular e que frequentam clínicas privadas ${ }^{38}$. Ou seja, conclui-se a existência de uma assimetria: um grupo que utiliza o Judiciário em demasia e outro conjunto de pessoas excluídas das formas tradicionais de resolução de controvérsias.

Para compreender melhor os fenômenos atuais na prestação dos serviços judiciais no Brasil, é necessário revisar as abordagens teóricas da literatura de acesso à justiça. A principal contribuição na área para o início dos debates foi

38 SADEK, Maria Tereza. Acesso à Justiça: Um direito e seus Obstáculos, p. 60. 
OLIVEIRA, Eduardo Matos. Transformações no acesso à justiça: da expansão do judiciário às soluções alternativas de conflitos. Revista Eletrônica Direito e Política, Programa de Pós-Graduação Stricto Sensu em Ciência Jurídica da UNIVALI, Itajaí, v.13, n.1, $1^{\circ}$ quadrimestre de 2018. Disponível em: www.univali.br/direitoepolitica - ISSN 1980-7791

relatório do Florence Project publicado originalmente em 1978 por Mauro Cappelletti e Bryant Garth. Os autores elaboraram um estudo comparado, a fim de compreender os principais obstáculos para a efetivação do acesso à justiça.

Originalmente, a partir das revoluções burguesas e na construção do Judiciário moderno, o direito à proteção judicial era equivalente ao direito formal do indivíduo propor ou contestar uma ação. Portanto, não cabia ao Estado intervir nos procedimentos de acesso aos tribunais, que ficavam restritos aos indivíduos que podiam arcar com os custos ${ }^{39}$. Inclusive, mesmo durante a segunda metade do século $X X$, os estudos a respeito do acesso à justiça ainda eram tipicamente formalistas e desprezavam os problemas reais enfrentados pela população em busca da materialização de seus direitos. Por isso, o estudo "Acesso à Justiça" de Cappelletti e Garth representa uma mudança de paradigma tão profunda na área.

O pressuposto básico da nova literatura que surge a partir do estudo em questão é que "a titularidade de direitos é destituída de sentido na ausência de mecanismos para sua efetiva reinvindicação" 40 . Por isso, torna-se imprescindível analisar quais são os obstáculos centrais não somente do acesso à justiça formal, mas também material.

Primeiramente, foi necessário tratar das barreiras econômicas. A duração do processo, o valor das custas processuais e honorários advocatícios são exemplos de questões que foram enfrentadas através da assistência judiciária para a população mais pobre. Os autores denominam este período como a primeira onda de acesso à justiça. Até a década de 1960, na Europa e nos Estados Unidos, o apoio jurídico às classes desfavorecidas era feito através de um sistema caritativo, sem contraprestação pecuniária aos advogados. Por

\footnotetext{
${ }^{39}$ CAPPELleTtI, Mauro; GARTH, Bryant. Acesso à Justiça. Porto Alegre: Fabris, 1988, p. 4. 40 CAPPELLETTI, Mauro; GARTH, Bryant. Acesso à Justiça, p. 5.
} 
OLIVEIRA, Eduardo Matos. Transformações no acesso à justiça: da expansão do judiciário às soluções alternativas de conflitos. Revista Eletrônica Direito e Política, Programa de Pós-Graduação Stricto Sensu em Ciência Jurídica da UNIVALI, Itajaí, v.13, n.1, 10 quadrimestre de 2018. Disponível em: www.univali.br/direitoepolitica - ISSN 1980-7791

conseguinte, a qualidade dos serviços era muito baixa e maior parte dos advogados não possuía experiência prévia ${ }^{41}$.

Durante a primeira onda do acesso à justiça foram estabelecidas duas principais formas de proporcionar o apoio jurídico para as classes desfavorecidas. No Reino Unido, o modelo do Judicare contratava advogados particulares pagos pelo Estado com honorários a preço de mercado. Nos Estados Unidos, ganhou força a ideia da advocacia pública priorizando a proximidade do contato entre os indivíduos e os advogados ${ }^{42}$.

Além de questões econômicas, há barreiras sociais e simbólicas que representam verdadeiros obstáculos ao cidadão comum. Por exemplo, a linguagem própria utilizada pelos juristas, excesso de formalismo nos procedimentos e a suntuosidade característica dos tribunais ${ }^{43}$. Luís Alberto Warat ${ }^{44}$ acrescenta ainda que vocabulário excessivamente técnico utilizado nas peças jurídicas é uma forma de "transformar sujeitos sociais em objetos de poder".

Além da questão da inclusão dos indivíduos pobres no sistema judicial (em outros âmbitos fora da esfera criminal), que constituiu a primeira onda de acesso à justiça, houve um segundo grande movimento durante a segunda metade do século XX: o problema da representação dos interesses difusos e coletivos. Segundo Cappelletti e Garth ${ }^{45}$ esta foi a segunda onda de acesso à justiça.

Ao afirmar que o problema básico destas questões se encontra no fato de que "o prêmio para qualquer indivíduo buscar essa correção é pequeno demais para

\footnotetext{
${ }^{41}$ CAPPELletTI, Mauro; GARTH, Bryant. Acesso à Justiça, p. 12.

42 PEDROSO, João; TRINCÃO, Catarina; DIAS, João Paulo. E a Justiça aqui tão perto? As transformações no acesso ao direito e à justiça. Revista Crítica de Ciências Sociais, n. 65, p.
} 77-106, 2003, p. 80.

43 SADEK, Maria Tereza. Acesso à Justiça: Um direito e seus Obstáculos, p. 58.

44 WARAT, Luis Alberto. Senso comum teórico: as vozes incógnitas das verdades jurídicas. In: Introdução Geral ao Direito: A epistemologia jurídica da modernidade - Vol. 1. Porto Alegre: SAFe, 1994.

45 CAPPELLeTTI, Mauro; GARTH, Bryant. Acesso à Justiça, p. 18. 
OLIVEIRA, Eduardo Matos. Transformações no acesso à justiça: da expansão do judiciário às soluções alternativas de conflitos. Revista Eletrônica Direito e Política, Programa de Pós-Graduação Stricto Sensu em Ciência Jurídica da UNIVALI, Itajaí, v.13, n.1, 10 quadrimestre de 2018. Disponível em: www.univali.br/direitoepolitica - ISSN 1980-7791

induzi-lo a tentar uma ação"46, os autores apontam para um problema de ação coletiva. Por exemplo, a poluição constante do ar em uma cidade, como foi o caso de Cubatão em São Paulo, pode acarretar diversos problemas para a população, no entanto os estímulos para que um cidadão comum busque individualmente uma solução são pequenos.

Antes dos problemas ambientais e de consumo se tornarem tão frequentes, a orientação do processo civil se dirigia unicamente a questões individuais. Como não existiam formas de resolver os conflitos coletivamente, os particulares eram obrigados a litigar individualmente. A pesquisa de Joaquim Falcão ${ }^{47}$ que analisou a inadimplência coletiva no sistema financeiro de habitação brasileiro nos anos 1980 e a representação coletiva por meio dos sindicatos concluiu que há uma "insuficiência do padrão liberal clássico em definir a natureza das partes conflitantes" ${ }^{\prime 4}$.

O autor ainda coloca que o Judiciário brasileiro nos 1980 não era a principal instância de resolução de conflitos coletivos na sociedade, conforme detalha na citação abaixo:

(...) esta recusa ou encolhimento do Judiciário não faz com que esses conflitos desapareçam ou percam intensidade. São apenas remetidos para outras arenas de resolução. Informais, paralelas, e mesmo ilegais. Em outras palavras, o Estado liberal abdica de equacionar os conflitos de seus cidadãos através de sua instituição especializada, o Judiciário, e através dos padrões substantivos de sua própria ordem legal ${ }^{49}$.

${ }^{46}$ CAPPELLETTI, Mauro; GARTH, Bryant. Acesso à Justiça, p. 10.

47 FALCÃO, Joaquim de Arruda. Cultura Jurídica e Democracia: A favor da democratização do judiciário. In: LAMOUNIER, Bolívar; WEFFORT, Francisco; BENEVIDES, Maria Victoria (orgs.). Direito, Cidadania e Participação. São Paulo: Tao, 1981.

48 FALCÃO, Joaquim de Arruda. Cultura Jurídica e Democracia: A favor da democratização do judiciário, p. 16.

49 FALCÃO, Joaquim de Arruda. Cultura Jurídica e Democracia: A favor da democratização do judiciário, p. 17. 
OLIVEIRA, Eduardo Matos. Transformações no acesso à justiça: da expansão do judiciário às soluções alternativas de conflitos. Revista Eletrônica Direito e Política, Programa de Pós-Graduação Stricto Sensu em Ciência Jurídica da UNIVALI, Itajaí, v.13, n.1, $1^{\circ}$ quadrimestre de 2018. Disponível em: www.univali.br/direitoepolitica - ISSN 1980-7791

Uma grande reformulação do processo civil foi feita para que o problema da representação coletiva fosse resolvido. Permitiu-se que uma instituição ou um indivíduo pudessem propor uma ação em nome da coletividade e também que os efeitos desta ação valessem para todos, mesmo que não tivessem sido ouvidos durante o processo. Por fim, cabe destacar o papel importante dos Ministérios Públicos, que em grande medida assumiram o papel da representação coletiva.

$\mathrm{Na}$ terceira onda de acesso à justiça, o debate central foi a respeito das formas alternativas de resolução de conflitos e simplificação dos procedimentos. Para Cappelletti e Garth ${ }^{50}$, essa abordagem "centra sua atenção no conjunto geral de instituições e mecanismos, pessoas e procedimentos utilizados para processar e mesmo prevenir disputas nas sociedades modernas".

Maria Tereza Sadek ${ }^{51}$ comenta que "o sistema de justiça é mais amplo do que o Poder Judiciário. A rigor, o juiz é apenas uma peça de um todo maior". A autora quebra a concepção corrente entre os operadores do direito de que o magistrado ocupa o lugar de destaque dentro dos mecanismos de acesso à justiça. A Defensoria Pública, a polícia investigativa, o Ministério Público, os advogados e outros atores exercem papel fundamental para 0 funcionamento dos procedimentos judiciais. Afinal, para a realização da justiça em sentido amplo, uma sentença judicial não é uma condição necessária nem suficiente.

A conciliação, mediação e arbitragem assumem um papel central em relação as novas mudanças engendradas no processo civil. Conforme destacam Cappelletti e Garth ${ }^{52}$ a "mediação ou outros mecanismos de interferência apaziguadora são os métodos mais apropriados para preservar os relacionamentos". Porém, os autores também destacam que existem conflitos nos quais a conciliação vai ser mais adequada, em outros a mediação e há também demandas mais complexas onde o papel do juiz e perito judicial será necessário.

\footnotetext{
50 CAPPELLETTI, Mauro; GARTH, Bryant. Acesso à Justiça, p. 25.

${ }^{51}$ SADEK, Maria Tereza. O Sistema de Justiça, p. 9.

52 CAPPELLeTTI, Mauro; GARTH, Bryant. Acesso à Justiça, p. 26.
} 
OLIVEIRA, Eduardo Matos. Transformações no acesso à justiça: da expansão do judiciário às soluções alternativas de conflitos. Revista Eletrônica Direito e Política, Programa de Pós-Graduação Stricto Sensu em Ciência Jurídica da UNIVALI, Itajaí, v.13, n.1, 10 quadrimestre de 2018. Disponível em: www.univali.br/direitoepolitica - ISSN 1980-7791

Além das ondas de acesso à justiça e a abordagem institucional desenvolvida por Cappelletti e Garth, há uma outra teoria que traz uma explicação alternativa para as transformações do Judiciário durante a segunda metade do século XX, trazida por Boaventura de Sousa Santos, Maria Manuel Leitão Marques e João Pedroso53. Para os autores, os diferentes programas de acesso à justiça não foram fruto de aperfeiçoamento institucional ou aprimoramento processual somente, mas sim estão diretamente ligados a dinâmicas econômicas mais gerais, especialmente o surgimento e a crise do Estado de Bem-Estar Social.

A leitura feita por esta abordagem sugere que os sistemas baseados em prestação de serviços de caridade por parte de advogados até a segunda Guerra Mundial eram decorrentes da visão liberal predominante na época, que não admitia uma maior intervenção do Estado. Com o surgimento do Welfare State, novas formas de litígios surgiram em campos que não existiam antes, tal como a seguridade social, novas fronteiras do direito do trabalho e direito administrativo. Consequentemente, houve um aumento exponencial na procura pelos serviços judiciais.

Portanto, as mudanças institucionais nas políticas de acesso ao Poder Judiciário seriam uma reposta aos novos desafios trazidos pelo Estado de Bem-Estar Social. De acordo com essa visão, a criação da assistência jurídica aos desfavorecidos através do Judicare ou da advocacia pública, os tribunais de pequenas causas, as formas alternativas de resolução de conflitos foram resultado destas mudanças mais amplas no campo político e econômico ${ }^{54}$. Inclusive, os autores argumentam que os direitos coletivos e difusos foram integrados à agenda judicial na medida em que movimentos sociais foram capazes de se mobilizar também no âmbito jurídico, a fim de pressionar os tribunais para analisar estas demandas.

\footnotetext{
53 SANTOS, Boaventura de Sousa; MARQUES, Maria Manuel Leitão; PEDROSO, João. Os Tribunais nas Sociedades Contemporâneas. Revista Brasileira de Ciências Sociais, vol. 11, n. 30, p. 2962, 1996.

54 SANTOS, Boaventura de Sousa; MARQUES, Maria Manuel Leitão; PEDROSO, João. Os Tribunais nas Sociedades Contemporâneas.
} 
OLIVEIRA, Eduardo Matos. Transformações no acesso à justiça: da expansão do judiciário às soluções alternativas de conflitos. Revista Eletrônica Direito e Política, Programa de Pós-Graduação Stricto Sensu em Ciência Jurídica da UNIVALI, Itajaí, v.13, n.1, 10 quadrimestre de 2018. Disponível em: www.univali.br/direitoepolitica - ISSN 1980-7791

Boaventura de Sousa Santos et al. ${ }^{55}$ fazem ainda uma conexão direta entre a maior atuação política do Judiciário enquanto poder do Estado e as medidas de acesso à justiça. Para eles, foi a necessidade de efetivação dos novos direitos econômicos e sociais que trouxe uma proeminência do Judiciário, já que no período liberal durante o século XIX, os juízes eram vistos como meros aplicadores da legislação. Haveria uma ligação entre a ascensão das legislações de direitos sociais nos países centrais e o movimento de ativismo judicial para colocá-los em prática.

Nos anos 1980 e 1990, com a crise do Estado de Bem-Estar Social também houve uma retração nas políticas de acesso à justiça, conforme a citação abaixo esclarece:

\begin{abstract}
Apesar do crescimento da procura do direito e da justiça na maior parte das sociedades, os requisitos de elegibilidade e de acesso ao sistema de apoio legal tornaram-se mais restritivos e foi introduzida ou desenvolvida a obrigatoriedade das contribuições dos utentes para o pagamento parcial (ou total) do custo de seus casos. As orientações políticas dos diversos governos foram no sentido de restringir o espectro de casos para os quais o apoio judiciário estava disponível, limitando-o progressivamente, nos países onde foi mais desenvolvido, aos casos criminais. Os critérios de elegibilidade para se ter direito aos meios de acesso ao direito e à justiça dos anos noventa retomaram os esquemas caritativos anteriores à Segunda Guerra Mundial ${ }^{56}$.
\end{abstract}

A perspectiva econômica a respeito do Welfare State parece muito útil para compreender a realidade europeia e norte-americana, todavia apresenta limitações para explicar o desenvolvimento do acesso à justiça no Brasil. Mesmo durante a década de 1990 em que o Brasil vivenciou governos de inclinação liberal, alguns órgãos como a Justiça do Trabalho, que possui uma função predominantemente social, não deixaram de se expandir. Portanto, conclui-se

55 SANTOS, Boaventura de Sousa; MARQUES, Maria Manuel Leitão; PEDROSO, João. Os Tribunais nas Sociedades Contemporâneas.

56 PEDROSO, João; TRINCÃO, Catarina; DIAS, João Paulo. E a Justiça aqui tão perto? As transformações no acesso ao direito e à justiça, p. 84. 
OLIVEIRA, Eduardo Matos. Transformações no acesso à justiça: da expansão do judiciário às soluções alternativas de conflitos. Revista Eletrônica Direito e Política, Programa de Pós-Graduação Stricto Sensu em Ciência Jurídica da UNIVALI, Itajaí, v.13, n.1, 10 quadrimestre de 2018. Disponível em: www.univali.br/direitoepolitica - ISSN 1980-7791

que os processos políticos e econômicos no Brasil e na Europa foram tão diferentes durante o século XX que há uma dificuldade para a comparação sobre a evolução dos mecanismos processuais.

\section{MUDANÇAS RECENTES NA POLÍTICA DE ACESSO À JUSTIÇA NO BRASIL}

A reforma do Judiciário por meio da emenda constitucional 45/2004 procurou remover obstáculos na prestação do serviço jurisdicional no Brasil. Foi inserido na Constituição o princípio da razoável duração do processo com o objetivo de destacar a importância da questão temporal para a efetivação da justiça. Em matéria penal, os tribunais demoram pelo menos duas vezes mais que o tempo estabelecido no código de processo penal para julgar os processos, segundo pesquisas levantadas por Ludmila Ribeiro ${ }^{57}$ no campo da sociologia do direito.

Naturalmente, apenas a inserção de um princípio constitucional sem ações práticas não resolverá o problema. Portanto, uma medida tomada foi o estabelecimento da proporcionalidade entre o número de juízes na unidade jurisdicional e a efetiva demanda judicial/população. Uma parte dos argumentos sobre a questão da morosidade processual tem como base o déficit de juízes no país apontando necessidade de expansão dos órgãos judiciais. É preciso destacar que esse déficit é muito diferente nas unidades da federação. Por exemplo, no estado de Sergipe não há diferença entre os cargos de juízes previstos em lei e aqueles que foram providos, enquanto que no estado do Amazonas essa diferença ultrapassa os $70 \%{ }^{58}$.

A emenda constitucional 45/2004 também estabeleceu o funcionamento ininterrupto da atividade jurisdicional através dos juízes de plantão nos dias em que não houver expediente forense normal, visto que muitas demandas surgem em feriados e fim de semana. A obrigação de distribuição imediata dos processos em todos os graus de jurisdição foi adicionada ao texto constitucional, a fim de contribuir para a celeridade processual. Em muitos casos, o processo demorava

57 RIBEIRO, Ludmila. A Emenda Constitucional 45 e a Questão do Acesso à Justiça. Revista Direito GV, vol. 4, n. 2, p. 465-492, 2008, p. 474.

58 RIBEIRO, Ludmila. A Emenda Constitucional 45 e a Questão do Acesso à Justiça, p. 476. 
OLIVEIRA, Eduardo Matos. Transformações no acesso à justiça: da expansão do judiciário às soluções alternativas de conflitos. Revista Eletrônica Direito e Política, Programa de Pós-Graduação Stricto Sensu em Ciência Jurídica da UNIVALI, Itajaí, v.13, n.1, 10 quadrimestre de 2018. Disponível em: www.univali.br/direitoepolitica - ISSN 1980-7791

vários anos apenas para ser distribuído no tribunal de segunda instância, além do tempo necessário para que o desembargador analisasse o mérito.

Importante citar também a criação dos juizados especiais federais, que foram autorizados anteriormente através da emenda constitucional 22/1999. Estes órgãos prestam um papel fundamental na simplificação dos procedimentos judiciais e foram regulamentados pela lei 10.259/2001, que estabeleceu o limite de sessenta salários mínimos como competência dos juizados para causas cíveis. A reforma do Judiciário posterior fortaleceu a iniciativa e apoiou a criação de novos juizados ${ }^{59}$.

Além do mais, a chamada reforma do Judiciário no Brasil fortaleceu a prestação dos serviços judiciais nas relações trabalhistas, conforme coloca Rogério Arantes:
A reforma constitucional do judiciário - que em algum momento chegou a cogitar abertamente a extinção da justiça trabalhista - terminou por fortalecê-la ainda mais. A emenda constitucional 45/2004 substituiu a expressão "relações de emprego" por "relações de trabalho", ampliando sobremaneira as competências para o julgamento de causas oriundas do mundo do trabalho em geral, e não apenas do emprego formal ${ }^{60}$.

Recentemente, talvez a maior inovação, em termos de acesso à justiça, no processo civil brasileiro tenha sido as discussões sobre a obrigatoriedade da conciliação e mediação. O Novo Código de Processo Civil estabelece a chamada audiência necessária de conciliação ou mediação, que seria obrigatória para todos os casos, exceto quando as duas partes manifestem expressamente que não desejam realizar a audiência (Art. 334, §4, I). Porém, a chamada Lei de Mediação (13.140/2015), no art. 27, estabelece a obrigatoriedade do procedimento sem que haja nenhuma ressalva.

\footnotetext{
59 ARANTES, Rogério B. "Judiciário: entre a Justiça e a Política" In: Lúcia Avelar; Antônio Octávio Cintra. (Org.). Sistema Político Brasileiro: uma introdução, p. 60.

60 ARANTES, Rogério B. "Judiciário: entre a Justiça e a Política" In: Lúcia Avelar; Antônio Octávio Cintra. (Org.). Sistema Político Brasileiro: uma introdução, p. 53.
} 
OLIVEIRA, Eduardo Matos. Transformações no acesso à justiça: da expansão do judiciário às soluções alternativas de conflitos. Revista Eletrônica Direito e Política, Programa de Pós-Graduação Stricto Sensu em Ciência Jurídica da UNIVALI, Itajaí, v.13, n.1, 10 quadrimestre de 2018. Disponível em: www.univali.br/direitoepolitica - ISSN 1980-7791

O conflito entre as normas ainda precisa ser resolvido pelos tribunais superiores. Entretanto, considerando que a Lei de Mediação é posterior ao Novo Código de Processo Civil e também é uma lei mais específica, existem fortes argumentos para defender a obrigatoriedade legal da realização das audiências de conciliação ou mediação.

Apesar do grande entusiasmo no mundo jurídico em relação às formas alternativas de resolução de conflitos, as pesquisas empíricas sobre o tema recomendam cuidado na aplicação irrestrita destes mecanismos. MenkelMeadow ${ }^{61}$ alerta para o fato de que a obrigatoriedade pode não ser benéfica para a sociedade, como, por exemplo, nos casos de aplicação compulsória da arbitragem para questões trabalhistas ou de consumo.

A autora levanta ainda a dúvida se o uso massivo das soluções alternativas não acentuaria as desigualdades raciais e socioeconômicas entre as partes litigantes, visto que caso haja um flagrante desiquilíbrio em um processo judicial, o juiz pode balancear ao proferir a sentença, o que é mais complicado durante o processo de mediação em face da não interferência do mediador. Além do mais, o fato de um indivíduo já ter participado do procedimento de mediação anteriormente pode acarretar uma vantagem em relação a outra parte. Em resumo, a utilização compulsória das soluções alternativas de conflitos está crescendo mundo afora, sem que seus resultados tenham sido testados de forma robusta62.

Em termos de estudos empíricos, a pesquisa de Marc Galanter ${ }^{63}$ a respeito das cortes norte-americanas observa uma queda abrupta nos casos que são decididos pelos tribunais. Nos Estados Unidos, os dados mostram que os casos decididos pelas cortes federais na esfera cível caíram de 11,5\% em 1962 para

61 MENKEL-MEADOW, Carrie. Do the Haves Come Out Ahead in Alternative Justice Systems? Repeat Players in ADR. Ohio State Journal on Dispute Resolution, v. 15, n. 1, p. 19-61, 1999.

62 MENKEL-MEADOW, Carrie. Do the Haves Come Out Ahead in Alternative Justice Systems? Repeat Players in ADR, p. 26.

63 GALANTER, Marc. The Vanishing Trial: An Examination of Trials and Related Matters in Federal and State Courts. Journal of Empirical Legal Studies, v. 1, n. 3, p. 459-570, 2004. 
OLIVEIRA, Eduardo Matos. Transformações no acesso à justiça: da expansão do judiciário às soluções alternativas de conflitos. Revista Eletrônica Direito e Política, Programa de Pós-Graduação Stricto Sensu em Ciência Jurídica da UNIVALI, Itajaí, v.13, n.1, 10 quadrimestre de 2018. Disponível em: www.univali.br/direitoepolitica - ISSN 1980-7791

$1,8 \%$ em $2002^{64}$. O autor especula sobre possíveis causas para a queda, que poderia ser uma mudança de mentalidade dos juízes, advogados e partes, ou também uma migração para o uso massivo das soluções alternativas de resolução de conflitos.

Destaque-se que enquanto o número absoluto de tribunais caiu nos Estados Unidos - de 5.802 em 1962 para 4.569 em 2002 - o número de advogados, o montante gasto com serviços judiciais e até o prestígio do direito no senso comum norte-americano aumentou durante este período ${ }^{65}$. Consequentemente, o argumento que demonstra a força das soluções alternativas de conflitos ganha relevância e mostra a necessidade de aprofundar os estudos empíricos na área, a fim de verificar se a mediação e outros procedimentos alternativos são responsáveis por essa queda.

No Brasil, houve esforços para compreender o surgimento dos processos de soluções alternativas de conflitos. Por exemplo, em 2005, o Ministério da Justiça através da secretaria de reforma do Judiciário fez um mapeamento dos programas alternativos de solução e administração de conflitos de caráter público ou não governamental. Os resultados do relatório mostraram que havia um considerável investimento público na área, porém a institucionalização dos programas, em termos de garantia de continuidade, ainda era precária ${ }^{66}$.

Há uma dificuldade na formação dos profissionais, já que o curso é muito curto (40 horas), o que pode comprometer todo o processo. Apesar de haver recursos para implementação dos projetos, não houve uma preocupação com o acompanhamento e avaliação das medidas adotadas, por conseguinte o

64 GALANTER, Marc. The Vanishing Trial: An Examination of Trials and Related Matters in Federal and State Courts, p. 459.

65 GALANTER, Marc. The Vanishing Trial: An Examination of Trials and Related Matters in Federal and State Courts, p. 460.

66 BRASIL. Ministério da Justiça. Secretaria de Reforma do Judiciário. Acesso à Justiça por Sistemas Alternativos de Administração de Conflitos: mapeamento nacional de programas públicos e não governamentais. Brasília, 2005. Disponível em: < http://www.acessoajustica.gov.br/pub/_downloads/downloads_acesso_justica.pdf> Acesso em: 05/07/2016, p. 14. 
OLIVEIRA, Eduardo Matos. Transformações no acesso à justiça: da expansão do judiciário às soluções alternativas de conflitos. Revista Eletrônica Direito e Política, Programa de Pós-Graduação Stricto Sensu em Ciência Jurídica da UNIVALI, Itajaí, v.13, n.1, 10 quadrimestre de 2018. Disponível em: www.univali.br/direitoepolitica - ISSN 1980-7791

aperfeiçoamento dos programas ficou prejudicado. Segundo o levantamento, quem mais utiliza os serviços são as classes populares (80\%), sobretudo mulheres ${ }^{67}$.

Em 2014, a secretaria de reforma do Judiciário em conjunto com a Fundação Getúlio Vargas publicou o "Estudo Qualitativo sobre Boas Práticas de Mediação no Brasil", que fez um estudo de caso com cinco centros judiciários de solução consensual de conflitos (Jundiaí, Caxias da Paz, Tucuruí, Campo Grande e Fortaleza). O objetivo da pesquisa foi estabelecer parâmetros para análise dos procedimentos de mediação nos centros observados por meio da institucionalização, nível de especialização, satisfação do público-alvo, cumprimento voluntário do acordo, entre outros ${ }^{68}$.

A pesquisa também pretendeu fazer uma avaliação da implantação destes centros de mediação por meio da percepção dos usuários em relação aos resultados do processo de mediação. A conclusão do estudo foi de que o grau de institucionalização do centro pode ser tomado como variável-chave para analisar o processo de mediação nos centros observados ${ }^{69}$. Todavia, é preciso ressaltar que o estudo qualitativo em cinco municípios não representa a realidade de todos os centros de mediação implantados no Brasil, apenas um levantamento estatístico pode apresentar a abrangência necessária para avaliar toda a política de estímulo a utilização destes métodos de solução de controvérsias.

\section{CONSIDERAÇÕES FINAIS}

A partir dos debates analisados, percebe-se que a literatura do acesso à justiça evoluiu não só no âmbito jurídico, mas também na esfera da Ciência Política.

67 BRASIL. Ministério da Justiça. Secretaria de Reforma do Judiciário. Acesso à Justiça por Sistemas Alternativos de Administração de Conflitos: mapeamento nacional de programas públicos e não governamentais, p. 14.

68 BRASIL. Ministério da Justiça. Secretaria de Reforma do Judiciário. Estudo Qualitativo sobre Boas Práticas em Mediação no Brasil. Brasília, 2014. Disponível em: <http://mediacao.fgv.br/wp-content/uploads/2015/11/Estudo-qualitativo-sobre-boas-praticas-emmediacao-no-Brasil.pdf> Acesso em: 07/07/2016, p. 5).

69 BRASIL. Ministério da Justiça. Secretaria de Reforma do Judiciário. Estudo Qualitativo sobre Boas Práticas em Mediação no Brasil, p. 166. 
OLIVEIRA, Eduardo Matos. Transformações no acesso à justiça: da expansão do judiciário às soluções alternativas de conflitos. Revista Eletrônica Direito e Política, Programa de Pós-Graduação Stricto Sensu em Ciência Jurídica da UNIVALI, Itajaí, v.13, n.1, $1^{\circ}$ quadrimestre de 2018. Disponível em: www.univali.br/direitoepolitica - ISSN 1980-7791

Porém, ainda existe pouco diálogo interdisciplinar entre os dois campos. O caso da obrigatoriedade da conciliação e mediação no novo Código de Processo Civil foi analisada para exemplificar como os estudos empíricos podem contribuir para enriquecer as discussões jurídicas atuais.

Seguramente, o campo do acesso à justiça pode ganhar força analítica a partir desta integração. Os estudos jurídicos podem oferecer as reflexões normativas que são imprescindíveis para estabelecer os rumos a serem seguidos tanto na academia como na elaboração de políticas públicas. Por outro lado, a Ciência Política oferece as ferramentas metodológicas necessárias para a avaliação e continuidade das políticas públicas.

As pesquisas empíricas são fundamentais a fim de verificar se os resultados obtidos na implantação das políticas correspondem ao que foi planejado. O IPEA, por exemplo, realizou uma avaliação de impacto da Lei Maria da Penha através do método estatístico da diferença da diferença, comparando o número de homicídios ocorridos contra mulheres dentro das residências após a promulgação da lei em comparação com os homicídios contra homens. Os resultados apontaram que a política foi bem-sucedida na redução da violência de gênero, todavia houve um efeito desigual nas regiões do país, já que a eficácia dependeu da institucionalização dos serviços protetivos, o que ocorreu de forma irregular geograficamente ${ }^{70}$.

Atualmente, existe uma quantidade significativa de dados a respeito de diversos programas existentes na prestação do serviço judicial. Entretanto, no âmbito acadêmico do Direito há uma lacuna técnica para realizar a análise dos dados, por isso a contribuição da Ciência Política pode ser tão valiosa, especialmente, considerando que existe uma literatura ativa na área do acesso à justiça. Dessa forma, será possível desenvolver uma política de acesso à justiça que seja orientada de forma coerente acerca de seus valores fundamentais e também testada efetivamente através de pesquisas empíricas.

70 CERQUEIRA, Daniel; MATOS, Mariana; MARTINS, Ana; JUNIOR, Jony. Avaliando a Efetividade da Lei Maria da Penha. In: IPEA texto para discussão 2048, p. 7-35, 2015. 
OLIVEIRA, Eduardo Matos. Transformações no acesso à justiça: da expansão do judiciário às soluções alternativas de conflitos. Revista Eletrônica Direito e Política, Programa de Pós-Graduação Stricto Sensu em Ciência Jurídica da UNIVALI, Itajaí, v.13, n.1, $1^{\circ}$ quadrimestre de 2018. Disponível em: www.univali.br/direitoepolitica - ISSN 1980-7791

\section{REFERÊNCIA DAS FONTES CITADAS}

ARANTES, Rogério B. "Judiciário: entre a Justiça e a Política" In: Lúcia Avelar; Antônio Octávio Cintra. (Org.). Sistema Político Brasileiro: uma introdução. São Paulo: Editora UNESP, 2014.

BITTAR, Eduardo; ALMEIDA, Guilherme Assis de. Curso de Filosofia do Direito. São Paulo: Editora Atlas, 2009.

BRASIL. Ministério da Justiça. Secretaria de Reforma do Judiciário. Acesso à Justiça por Sistemas Alternativos de Administração de Conflitos: mapeamento nacional de programas públicos e não governamentais. Brasília, 2005.

Disponível em:

http://www.acessoajustica.gov.br/pub/_downloads/downloads_acesso_justica.pd f> Acesso em: 05/07/2016.

. Ministério da Justiça. Secretaria de Reforma do Judiciário. Estudo

Qualitativo sobre Boas Práticas em Mediação no Brasil. Brasília, 2014. Disponível em: <http://mediacao.fgv.br/wp-content/uploads/2015/11/Estudoqualitativo-sobre-boas-praticas-em-mediacao-no-Brasil.pdf $>$ Acesso em: 07/07/2016.

CAPPELLETTI, Mauro; GARTH, Bryant. Acesso à Justiça. Porto Alegre: Fabris, 1988.

CARVALHO, Ernani. Revisão Judicial e Judicialização da Política no Direito Ocidental: Aspectos relevantes de sua gênese e desenvolvimento. Revista de Sociologia e Política, n. 28, p. 161-179, 2007.

CERQUEIRA, Daniel; MATOS, Mariana; MARTINS, Ana; JUNIOR, Jony. Avaliando a Efetividade da Lei Maria da Penha. In: IPEA texto para discussão 2048, p. 7-35, 2015.

CONSELHO NACIONAL DE JUSTIÇA. Cem maiores litigantes. Brasília, 2011. Disponível em: <http://www.cnj.jus.br/images/pesquisasjudiciarias/pesquisa_100_maiores_litigantes.pdf $\geq$. Acesso em 18 de maio de 2016.

DAHL, Robert. Um Prefácio à Teoria Democrática. Rio de Janeiro: Jorge Zahar Editor, 1989.

A Democracia e seus Críticos. São Paulo: Editora WMF Martins Fontes, 2012.

DWORKIN, Ronald. O Direito da Liberdade - A Leitura Moral da Constituição Norte-Americana. São Paulo: Editora Martins Fontes, 2006.

A Virtude Soberana - A Teoria e a Prática da Igualdade. São Paulo, Editora Martins Fontes, 2011. 
OLIVEIRA, Eduardo Matos. Transformações no acesso à justiça: da expansão do judiciário às soluções alternativas de conflitos. Revista Eletrônica Direito e Política, Programa de Pós-Graduação Stricto Sensu em Ciência Jurídica da UNIVALI, Itajaí, v.13, n.1, $1^{\circ}$ quadrimestre de 2018. Disponível em: www.univali.br/direitoepolitica - ISSN 1980-7791

FALCÃO, Joaquim de Arruda. Cultura Jurídica e Democracia: A favor da democratização do judiciário. In: LAMOUNIER, Bolívar; WEFFORT, Francisco; BENEVIDES, Maria Victoria (orgs.). Direito, Cidadania e Participação. São Paulo: Tao, 1981.

FAREJOHN, John. Judicializing Politics, Politicizing Law. Law and Contemporary Problems, vol. 65, n. 3, 2002.

GALANTER, Marc. The Vanishing Trial: An Examination of Trials and Related Matters in Federal and State Courts. Journal of Empirical Legal Studies, v. 1, n. 3, p. 459-570, 2004.

KELSEN, Hans. Quem deve ser o Guardião da Constituição? In: KELSEN, Hans. Jurisdição Constitucional. São Paulo: Editora Martins Fontes, 2003.

MADISON, James; HAMILTON, Alexander; JAY, John. Os Artigos Federalistas, 1787-1788. Rio de Janeiro: Editora Nova Fronteira, 1993.

MENKEL-MEADOW, Carrie. Do the Haves Come Out Ahead in Alternative Justice Systems? Repeat Players in ADR. Ohio State Journal on Dispute Resolution, v. 15, n. 1 , p. $19-61,1999$.

MONTESQUIEU. O Espírito das Leis. São Paulo: Martins Fontes, 1996.

OLIVEIRA, Luciano. Sua Excelência o Comissário e outros ensaios de Sociologia Jurídica. Rio de Janeiro: Editora Letra Legal, 2004.

PEDROSO, João; TRINCÃO, Catarina; DIAS, João Paulo. E a Justiça aqui tão perto? As transformações no acesso ao direito e à justiça. Revista Crítica de Ciências Sociais, n. 65, p. 77-106, 2003.

RIBEIRO, Ludmila. A Emenda Constitucional 45 e a Questão do Acesso à Justiça. Revista Direito GV, vol. 4, n. 2, p. 465-492, 2008.

SADEK, Maria Tereza (org.). Acesso à Justiça. São Paulo: Fundação Konrad Adenauer, 2001.

Pesquisas Sociais, 2010.

O Sistema de Justiça. Rio de Janeiro: Centro Edelstein de Acesso à Justiça: Um direito e seus Obstáculos. Revista USP, n. 101, p. 55-66, 2014.

SANTOS, Boaventura de Sousa; MARQUES, Maria Manuel Leitão; PEDROSO, João. Os Tribunais nas Sociedades Contemporâneas. Revista Brasileira de Ciências Sociais, vol. 11, n. 30, p. 29-62, 1996.

TATE, Neal; VALLINDER, Torbjörn. The Global Expansion of Judicial Power. New York: New York University Press, 1995. 
OLIVEIRA, Eduardo Matos. Transformações no acesso à justiça: da expansão do judiciário às soluções alternativas de conflitos. Revista Eletrônica Direito e Política, Programa de Pós-Graduação Stricto Sensu em Ciência Jurídica da UNIVALI, Itajaí, v.13, n.1, $1^{\circ}$ quadrimestre de 2018. Disponível em: www.univali.br/direitoepolitica - ISSN 1980-7791

TAYLOR, Matthew. O Judiciário e as Políticas Públicas no Brasil. DADOS Revista de Ciências Sociais, vol. 50, n. 2, p. 229-257, 2007.

WALDRON, Jeremy. The Core of the Case Against Judicial Review. The Yale Law Journal, n. 115, 2006.

WARAT, Luis Alberto. Senso comum teórico: as vozes incógnitas das verdades jurídicas. In: Introdução Geral ao Direito: A epistemologia jurídica da modernidade - Vol. 1. Porto Alegre: SAFe, 1994.

Submetido em: 20/02/2018

Aprovado em: 29/03/2018 